\title{
Erratum to: Detection of the M268T mutation angiotensinogen gene based on screen-printed electrodes modified with a nanocomposite: application to human genomic samples
}

\author{
Mohammad Mazloum-Ardakani $^{1} \cdot$ Laleh Hosseinzadeh $^{1} \cdot$ Mohammad Mehdi Heidari $^{2}$
}

Published online: 9 November 2015

(C) Springer-Verlag Wien 2015

Erratum to: Microchim Acta

DOI 10.1007/s00604-015-1616-3

The original version of this paper, unfortunately, contained an error.

The original title, "Detection of the M268T Angiotensinogen A3B2 mutation gene based on screen-printed electrodes modified with a nanocomposite: application to human genomic samples", was incorrect.

The correct title should be "Detection of the M268T mutation angiotensinogen gene based on screen-printed electrodes modified with a nanocomposite: application to human genomic samples", which is now given in this article.

The online version of the original article can be found at http://dx.doi.org/ 10.1007/s00604-015-1616-3.

Mohammad Mazloum-Ardakani

mazloum@yazd.ac.ir

1 Department of Chemistry, Faculty of Science, Yazd University,

Yazd 89195-741, Iran

2 Department of Biology, Faculty of Science, Yazd University,

Yazd 89195-741, Iran 